\title{
Validation of PigBal model predictions for pig manure production
}

\author{
A. G. Skerman ${ }^{\mathrm{A}, \mathrm{D}}$, S. Willis ${ }^{\mathrm{A}}$, E. J. McGahan ${ }^{\mathrm{B}}$, M. G. Borgognone ${ }^{\mathrm{A}}$ and D. J. Batstone ${ }^{\mathrm{C}}$ \\ A Department of Agriculture, Fisheries and Forestry, Toowoomba, Qld 4350, Australia. \\ ${ }^{B}$ FSA Consulting, Toowoomba, Qld 4350, Australia. \\ ${ }^{C}$ Advanced Water Management Centre, University of Queensland, St Lucia, Qld 4072, Australia. \\ ${ }^{D}$ Corresponding author. Email: alan.skerman@daff.qld.gov.au
}

\begin{abstract}
PigBal is a mass balance model that uses pig diet, digestibility and production data to predict the manure solids and nutrients produced by pig herds. It has been widely used for designing piggery effluent treatment systems and sustainable reuse areas at Australian piggeries. More recently, PigBal has also been used to estimate piggery volatile solids production for assessing greenhouse gas emissions for statutory reporting purposes by government, and for evaluating the energy potential from anaerobic digestion of pig effluent. This paper has compared PigBal predictions of manure total, volatile, and fixed solids, and nitrogen $(\mathrm{N})$, phosphorus $(\mathrm{P})$ and potassium $(\mathrm{K})$, with manure production data generated in a replicated trial, which involved collecting manure from pigs housed in metabolic pens. Predictions of total, volatile, and fixed solids and $\mathrm{K}$ in the excreted manure were relatively good (combined diet $R^{2} \geq 0.79$, modelling efficiency $(\mathrm{EF}) \geq 0.70$ ) whereas predictions of $\mathrm{N}$ and $\mathrm{P}$, were generally less accurate (combined diet $R^{2} 0.56$ and $0.66, \mathrm{EF}$ 0.19 and -0.22 , respectively). PigBal generally under-predicted lower $\mathrm{N}$ values while over-predicting higher values, and generally over-predicted manure $\mathrm{P}$ production for all diets. The most likely causes for this less accurate performance were ammonium-N volatilisation losses between manure excretion and sample analysis, and the inability of PigBal to account for higher rates of $\mathrm{P}$ uptake by pigs fed diets containing phytase. The outcomes of this research suggest that there is a need for further investigation and model development to enhance PigBal's capabilities for more accurately assessing nutrient loads. However, PigBal's satisfactory performance in predicting solids excretion demonstrates that it is suitable for assessing the methane component of greenhouse gas emission and the energy potential from anaerobic digestion of volatile solids in piggery effluent. The apparent overestimation of $\mathrm{N}$ and $\mathrm{P}$ excretion may result in conservative nutrient application rates to land and the over-prediction of the nitrous oxide component of greenhouse gas emissions.
\end{abstract}

Additional keywords: diet, effluent, nutrients, solids.

Received 17 July 2014, accepted 1 December 2014, published online 20 February 2015

\section{Introduction}

The PigBal model is used to predict the manure solids and nutrients produced by pig herds. The major inputs to the model include characteristics of the individual diet ingredients, feed intakes, and pig production data. Version 1 of the PigBal model (Casey et al. 1996) incorporated the Digestibility Approximation of Manure Production (DAMP) methodology (Barth 1985), which was used in conjunction with a mass balance approach to predict the masses of total solids (TS), volatile solids (VS), fixed solids (FS) or ash, nitrogen (N), phosphorus $(\mathrm{P})$ and potassium $(\mathrm{K})$ in piggery manure. McGahan et al. (2000) improved the original model by replacing the DAMP methodology with the Dry Matter Digestibility Approximation of Manure Production (DMDAMP) methodology developed by McGahan and Casey (1998). The DMDAMP methodology uses Dry Matter
Digestibility (DMD) estimates of feed ingredients in place of the Total Digestible Nutrients (TDN) data used in the DAMP methodology.

Since the model was first developed, PigBal has been widely used to estimate TS and VS for designing piggery effluent treatment systems and $\mathrm{N}, \mathrm{P}$ and $\mathrm{K}$ for designing sustainable reuse areas in the Australian pig industry. More recently, PigBal has also been used to estimate piggery VS and $\mathrm{N}$ production for the purpose of estimating greenhouse gas (GHG) emissions from manure management systems and land application. The Australian Government's Department of Climate Change and Energy Efficiency methodology, used for preparing returns under the National Greenhouse Gas Inventories (DCCEE 2011), specifically uses PigBal model estimates to provide data on piggery VS and $\mathrm{N}$ production. Use of PigBal is also specified under the Carbon Farming (Destruction of 
Methane Generated from Manure in Piggeries) Methodology Determination 2012 (Federal Register of Legislative Instruments F2012L01501 2012).

With recent increasing interest in installing anaerobic digestion systems to reduce GHG emissions and to enable the use of biogas to offset rising on-farm energy costs at Australian piggeries, the VS estimates produced by PigBal have assumed an even greater economic value and importance.

The current version of PigBal (version 4) incorporates recommendations made by McGahan et al. (2010), including rectification of an error which affected VS, FS, N, P and K predictions. It also incorporates the updated feed ingredient list (Willis 2010) and several other enhancements, which did not directly influence manure production predictions.

This paper describes the experimental trial undertaken to collect the data used to validate the model, the model validation process and results.

\section{Materials and methods}

\section{Metabolic pen trial}

The trial involved feeding four different diets to 16 male grower/ finisher pigs accommodated in metabolic pens, over a total period of 13 weeks. Whole manure was sampled during alternate weeks (six samples per pig). The 16 raised metabolic pens used in this trial were constructed using galvanised steel piping and mesh panels, with fully slatted Polygrate flooring (Sigma Industries Inc., Saint-Éphrem-de-Beauce (Québec), Canada), manufactured from a plastic/fibreglass composite material. The pen dimensions were $1.4 \mathrm{~m}$ long $\times 0.7 \mathrm{~m}$ wide, resulting in a floor area of $\sim 0.98 \mathrm{~m}^{2} / \mathrm{pig}$. Each of the 16 pigs used in the experiment were allocated to individual pens. Clear plastic sheeting was secured under each of the pen floors to form a sloping drain to direct the manure (faeces and urine) and waste drinking water into a collection bucket, placed under the opposite end of the pen from the feeder.

On 15 February 2011, 18 large white male pigs (16 trial pigs + two spares) were selected on a uniform liveweight basis, from a batch of pigs bred at the University of Queensland (UQ) piggery, located near Gatton, in southern Queensland. At the commencement of the trial, the 16 selected pigs had an average age of 7.7 weeks (range 6.7-8.9 weeks) and an average liveweight of $16.1 \mathrm{~kg}$ (range $14.5-17.5 \mathrm{~kg}$ ).

The 16 trial pigs were randomly allocated to four different diets (four replicates per diet). A randomised complete block design was used to allocate the pigs to four blocks of the individual raised metabolic pens, set up in building 8378 at the Centre for Advanced Animal Science, located at the UQ Gatton campus. The 16 trial pigs were identified according to the four diets (A-D) and numbers from 1 to 16 . The two spare pigs were accommodated in the same building, in adjacent raised pens. These spare pigs were to be introduced into the trial in the event of serious illness, injury or death occurring in any of the trial pigs.

The four diets, which were formulated with a digestible energy (DE) content of $14.0 \mathrm{MJ} / \mathrm{kg}$ and an available lysine content of $0.65 \mathrm{~g} / \mathrm{MJ} \mathrm{DE}$, were prepared by a commercial feed company, in bagged, pelleted form. The main ingredients in the four diets (\% mass as-fed) were: $\operatorname{diet}$ A: $72 \%$ wheat, 10\% barley (WB); diet B: $55 \%$ sorghum, $20 \%$ wheat (SW); diet C: $65 \%$ wheat, $10 \%$ mung beans, 10\% sorghum (WMS); diet D: 48\% barley, $20 \%$ wheat and 20\% mung beans (BWM). The bagged feed was stored in a refrigerated container situated adjacent to the trial building.

The pigs were pre-conditioned in the raised pens for a period of 2 weeks, before the first manure sample collection week, which commenced on 1 March 2011. Throughout the trial, the pigs were fed twice daily, at 7:00 a.m. and 3:00 p.m., at rates consistent with commercial practice to achieve optimum growth, with an additional 5\% allowance for feed wastage. Approximately half the daily ration was fed at each of the twice-daily feeding times. The mass of feed given to each pig was generally increased on a daily basis, up to the nominal amounts shown in Table 1, by the end of each week. The daily amounts fed to individual pigs were occasionally reduced if significant feed residue was observed in the feeders.

Drinking water was supplied by gravity through bite nipples and $12-\mathrm{mm}$ hosing connected to $20-\mathrm{L}$ drums installed on the tops of each of the raised pens. The drums were filled to a set mark at the twice-daily feeding times and the volumes of water required to top up the individual drums were recorded throughout the trial.

During the six alternate 1-week manure sampling periods, feed residues produced by each individual pig were collected twice daily, at feeding times. Waste feed that fell onto the pen floor, the plastic sheeting beneath the pen floor and the trial room floor, was manually collected in a feed residue container, along with any residue remaining in the feeder at the next feeding time. This feed residue collection procedure effectively eliminated any waste feed from entering the manure collection buckets. At the end of each manure sampling week, the feed residues were oven-dried, weighed and recorded for each of the individual trial pigs. These records were used to calculate the feed intake by each pig during the manure sampling weeks.

All of the manure (faeces and urine) excreted by each individual pig was also collected along with the waste drinking water during the alternate sample collection weeks.

Table 1. Trial stage descriptions, average pig ages and nominal feed fed (as-fed masses) at weekly intervals throughout the trial

\begin{tabular}{llcc}
\hline Trial day & Trial stage & $\begin{array}{c}\text { Average age } \\
\text { (weeks) }\end{array}$ & $\begin{array}{c}\text { Nominal feed } \\
\text { fed }^{\mathrm{A}}(\mathrm{kg} / \text { day })\end{array}$ \\
\hline 0 & Trial start & 7.7 & - \\
7 & Pre-condition 1 & 8.7 & 0.74 \\
14 & Pre-condition 2 & 9.7 & 0.89 \\
21 & Sample collection 1 & 10.7 & 1.05 \\
28 & & 11.7 & 1.21 \\
35 & Sample collection 2 & 12.7 & 1.37 \\
42 & & 13.7 & 1.63 \\
49 & Sample collection 3 & 14.7 & 1.84 \\
56 & & 15.7 & 2.05 \\
63 & Sample collection 4 & 16.7 & 2.21 \\
70 & & 17.7 & 2.36 \\
77 & Sample collection 5 & 18.7 & 2.57 \\
84 & & 19.7 & 2.73 \\
91 & Sample collection 6 & 20.5 & 2.89 \\
\hline
\end{tabular}

${ }_{\mathrm{A}}^{\mathrm{A}}$ ncludes an allowance for $5 \%$ feed wastage in addition to nominal feed intake. 
The majority of the manure and waste drinking water fell through the slatted pen floors onto the plastic sheeting, before draining into the manure collection buckets; however, some of the faeces had to be manually scraped from the slatted floor and plastic sheeting on a daily basis. Because the pigs had sufficient space to freely turn around in the raised pens throughout the majority of the trial period, some of the faeces fell onto the trial room floor, requiring manual collection and transfer into the collection buckets.

Pig metabolism studies often separate the urine, faeces and waste water into separate collection streams, allowing for the preservation of the urine $\mathrm{N}$ by acidification. This practice was not adopted in this study in an effort to simulate an intensive piggery environment where these components are combined in the effluent stream, and to allow for a range of different analyses on the composite samples.

The contents of each of the manure collection buckets were transferred, on a daily basis, into larger 20-25-L buckets stored in the refrigerated container located adjacent to the trial building. This container was maintained at an average temperature of $7^{\circ} \mathrm{C}$ throughout the trial period.

At the end of each collection week, all of the manure collected for each pig during the preceding week was homogenised by tipping the contents of the collection buckets through a sieve into a large mixing tub. A scraper was used to manually break up the solid material remaining in the sieve. A paddle was used to manually agitate the composite manure samples before subsampling into wide-mouthed 1-L sampling bottles.

The manure sample bottles for each individual pig were placed on ice in cooler boxes and transported to the Advanced Water Management Centre laboratory at the UQ St Lucia campus.

The pig liveweights were recorded weekly. Following consultation with a vet, one of the trial pigs was dispatched 1 week before the end of the trial due to an emerging health issue.

At the end of the 11-week sampling period, the remaining 15 pigs were dispatched to an abattoir for slaughter, at an average age of 20.5 weeks (range 19.6-21.7 weeks). The abattoir supplied hot standard carcass weight, kill-out percentage and back fat data for each of the individual pigs.

\section{Manure sample analyses}

The UQ Advanced Water Management Centre laboratory carried out a range of analyses on individual pig manure samples, for each of the six sampling weeks.

Total solids, VS and FS (ash) were analysed in triplicate according to standard methods (American Public Health Association 1998). The samples analysed for P and K were solubilised using acid digestion, followed by microwave digestion, before being analysed using Inductively Coupled Plasma Optical Emission Spectroscopy (Perkin Elmer Optima 7300DV, Waltham, MA, USA).

The samples analysed for total Kjeldahl $\mathrm{N}$ were centrifuged at $2500 \mathrm{~g}$ and the supernatant filtered through a syringe filter (0.4- $\mu \mathrm{m}$ PES membrane). The solutions were further diluted with Milli-Q water such that the concentrations of the samples were within the range of the standards. The diluted samples were analysed on a Flow Injection Analyser (Lachat QuikChem8000, Lachat Instruments, Loveland, CO, USA) using the QuikChem method.
Every time a new $25-\mathrm{kg}$ bag of feed was opened, $\sim 100 \mathrm{~g}$ of feed was subsampled from the contents of the bag and added to one of four composite samples for each diet type, stored in separate drums inside the refrigerated container. At the end of the trial, the composite samples retained for each diet type were subsampled into 1-L containers, which were forwarded to a commercial laboratory for analysis of nutrient and chemical composition.

\section{Statistical analyses}

Linear mixed models with smooth polynomial lines (splines) (Verbyla et al. 1999) were fitted to the pig liveweight, feed intake and excreted manure data, for the four diets, across the experimental period. These models included fixed effects for diet, days from the beginning of the experiment, and their interaction. The model included random effects for mean spline, diet and pig spline terms and their deviations. The shape of the spline was allowed to be different for each of the diets, and also for each pig within each diet, in order to account for as much variability as possible.

Predictions for the mean spline for each diet were obtained across the duration of the experiment, and 95\% confidence intervals around them were calculated. The diets were considered not significantly different (at the 5\% level) where the confidence intervals overlapped. Analyses were performed using the package ASReml-R (Butler et al. 2009).

ANOVA was performed for all pig performance traits. The data analysed included the overall average values of feed intake, across the duration of the experiment, for each replicate in each diet (Table 2). The model included replicate, diet and a residual term. Least Significant Difference (1.s.d.) tests were performed at the $5 \%$ level for the traits that showed a significant effect of diet, to determine which diets were significantly different from each other. The ANOVA procedure of the GENSTAT software (Payne et al. 2011) was used. To test the effect of diet on manure production, ANCOVA (anovan command in Matlab) was done to correct for the effect of age as a linear regressor.

Statistical validation measures for the combined and individual diet data were calculated, as suggested by Mayer and Butler (1993), to assist in validating the PigBal predictions against the trial data. These included modelling efficiency (EF) and simple linear regression parameters $\left(R^{2}\right.$, slope and intercept $)$ from fitting the measured trait as response and the PigBal estimate as explanatory variables.

The calculated EF is an overall measure of agreement between observed and simulated values (Mayer and Butler 1993). An EF value of 1 corresponds to a perfect match of modelled data to the observed data. An EF value of 0 indicates that the model predictions are as accurate as the mean of the observed data, whereas an EF value less than 0 occurs when the observed mean is a better predictor than the model. Essentially, the closer the EF value is to 1 , the more accurate the model is, and any model with a negative EF cannot be recommended.

\section{Model validation}

Various visual and quantitative methods were used to compare the experimental results (measured data) with the estimated waste outputs determined using the PigBal model (predicted data) for the manure TS, VS, FS (ash), N, P and K. 
Table 2. Pig performance, manure production and dietary nutrient mean values for the combined and four individual diets a, b, c, d, Means in a row with different letters differ significantly $(P<0.05)$. ADG, average daily (liveweight) gain; BWM, barley-wheat-mung beans; DMD, dry matter digestibility; FCR, feed conversion ratio (feed fed/liveweight gain); FS, fixed solids; HSCW, hot standard carcass weight; s.e.m., standard error of the mean; SW, sorghum-wheat; TS, total solids; VS, volatile solids; WB, wheat-barley; WMS, wheat-mung beans-sorghum

\begin{tabular}{|c|c|c|c|c|c|c|c|c|}
\hline Parameter & Units & $\begin{array}{c}\text { Combined } \\
\operatorname{diets}^{\mathrm{A}}\end{array}$ & $\begin{array}{c}\text { Diet A } \\
\text { (WB) }\end{array}$ & $\begin{array}{l}\text { Diet B } \\
\text { (SW) }\end{array}$ & $\begin{array}{c}\text { Diet C } \\
\text { (WMS) }\end{array}$ & $\begin{array}{l}\text { Diet D } \\
(\mathrm{BWM})\end{array}$ & s.e.m. & $P$-value ${ }^{\mathrm{B}}$ \\
\hline \multicolumn{9}{|c|}{ Performance } \\
\hline Start age & Weeks & 9.7 & 9.8 & 9.5 & 9.7 & 9.7 & 0.23 & 0.856 \\
\hline End age & Weeks & 20.6 & 20.7 & 20.4 & 20.6 & 20.5 & 0.23 & 0.856 \\
\hline Start liveweight & $\mathrm{kg} / \mathrm{pig}$ & 21.5 & 21.5 & 22.4 & 20.8 & 21.5 & 0.49 & 0.192 \\
\hline End liveweight & $\mathrm{kg} /$ pig & 90.0 & $89.0 \mathrm{~b}$ & $98.2 \mathrm{a}$ & $82.6 \mathrm{c}$ & $92.1 \mathrm{~b}$ & 1.39 & $<0.001$ \\
\hline Mean feed intake & kg/pig.day & 1.90 & 1.90 & 1.87 & 1.91 & 1.91 & 0.026 & 0.913 \\
\hline ADG (trial period) & kg/pig.day & 0.91 & $0.89 b$ & $1.00 \mathrm{a}$ & $0.81 \mathrm{c}$ & $0.93 b$ & 0.016 & $<0.001$ \\
\hline ADG (from birth) & kg/pig.day & 0.62 & $0.61 b$ & $0.68 \mathrm{a}$ & $0.56 \mathrm{c}$ & $0.63 b$ & 0.010 & $<0.001$ \\
\hline FCR & - & 2.09 & $2.12 b$ & $1.89 \mathrm{c}$ & $2.32 \mathrm{a}$ & $2.03 \mathrm{~b}$ & 0.034 & $<0.001$ \\
\hline HSCW & $\mathrm{kg} / \mathrm{pig}$ & 69.5 & $68.7 \mathrm{~b}$ & $75.8 \mathrm{a}$ & $63.8 \mathrm{c}$ & $71.5 b$ & 1.43 & $<0.001$ \\
\hline Kill out \% & $\%$ & 77.3 & 77.2 & 77.2 & 77.2 & 77.7 & 0.60 & 0.881 \\
\hline Back fat P2 & $\mathrm{mm}$ & 11.7 & 11.3 & 11.3 & 13.0 & 11.0 & 0.85 & 0.281 \\
\hline \multicolumn{9}{|c|}{ Manure (mean) } \\
\hline TS & kg/pig.day & 0.24 & $0.22 b$ & $0.23 b$ & $0.22 b$ & $0.29 \mathrm{a}$ & $0.004^{\mathrm{C}}$ & $<0.001^{\mathrm{D}}$ \\
\hline VS & kg/pig.day & 0.18 & $0.16 \mathrm{~b}$ & $0.16 b$ & $0.17 \mathrm{~b}$ & $0.23 \mathrm{a}$ & $0.004^{\mathrm{C}}$ & $<0.001^{\mathrm{D}}$ \\
\hline $\mathrm{VS} / \mathrm{TS}$ & & 0.74 & $0.72 \mathrm{c}$ & $0.68 \mathrm{~d}$ & $0.76 b$ & $0.79 \mathrm{a}$ & $0.005^{\mathrm{C}}$ & $<0.001^{\mathrm{D}}$ \\
\hline FS (ash) & kg/pig.day & 0.062 & $0.063 \mathrm{~b}$ & $0.076 \mathrm{a}$ & $0.053 \mathrm{c}$ & $0.061 b$ & $0.001^{\mathrm{C}}$ & $<0.001^{\mathrm{D}}$ \\
\hline Nitrogen & g/pig.day & 26.83 & $32.90 \mathrm{a}$ & $27.48 b$ & $30.87 \mathrm{ab}$ & $16.23 \mathrm{c}$ & $0.9^{\mathrm{C}}$ & $<0.001^{\mathrm{D}}$ \\
\hline Phosphorus & g/pig.day & 5.26 & $6.59 \mathrm{a}$ & $6.16 \mathrm{a}$ & $3.70 \mathrm{c}$ & $4.81 \mathrm{~b}$ & $0.2^{\mathrm{C}}$ & $<0.001^{\mathrm{D}}$ \\
\hline Potassium & g/pig.day & 7.75 & $8.30 \mathrm{a}$ & $7.72 b$ & $8.43 \mathrm{a}$ & $6.53 \mathrm{c}$ & $0.1^{\mathrm{C}}$ & $<0.001^{\mathrm{D}}$ \\
\hline \multicolumn{9}{|c|}{ Diet (laboratory analysis) } \\
\hline Nitrogen & $\mathrm{mg} / \mathrm{kg}$ & - & 33440 & 30400 & 29280 & 22720 & - & - \\
\hline Phosphorus & $\mathrm{mg} / \mathrm{kg}$ & - & 7240 & 7380 & 4660 & 5570 & - & - \\
\hline Potassium & $\mathrm{mg} / \mathrm{kg}$ & - & 5600 & 5630 & 5710 & 5110 & - & - \\
\hline DMD (PigBal) & $\%$ & - & 84.55 & 83.40 & 84.73 & 82.99 & - & - \\
\hline
\end{tabular}

${ }^{\mathrm{A}}$ Results based on averaged data from the four dietary treatments for each pig.

${ }^{\mathrm{B}} P$-value for significance of diet effect in ANOVA.

${ }^{\mathrm{C}}$ Standard error following correction for pig age by regression.

${ }^{\mathrm{D}}$ Corrected for pig age via ANCOVA.

Tabulated statistical validation measures, as suggested by Mayer and Butler (1993), are presented along with measured versus predicted regression plots for the combined and individual diet data. In combination, these graphs and tabulated data have been used to assess the performance of the PigBal model for predicting piggery waste production parameter values.

\section{Results}

\section{Pig performance}

The mean pig performance and manure production results are summarised in Table 2 and the pig liveweight and feed intake values are plotted across the duration of the trial in Fig. 1.

There were no significant differences between the mean ages or mean starting liveweights of the pigs allocated to the four diets. Additionally, there were no significant differences between the mean feed intakes per pig for the four diets, over the trial period.

The mean average daily gain (ADG), from birth to the end of the trial, was $0.616 \mathrm{~kg} / \mathrm{pig}$.day. This value is $7.6 \%$ lower than the mean ADG (birth to sale) value of $0.667 \mathrm{~kg} /$ pig.day reported in the recent Pork CRC benchmarking results (Campbell 2013) for a range of Australian piggeries; however, the diet $\mathrm{B}$ pigs recorded a mean $\mathrm{ADG}$ value higher than the $\mathrm{CRC}$ benchmark value.
The mean feed conversion ratio (FCR) values for the four diets ranged from 1.89 to 2.32 , with an overall mean value of 2.09. These results are consistent with the recently released Pork CRC benchmarking results (Campbell 2013), which reported an average wean-finish FCR of 2.38. The trial FCR results were expected to be lower than commercial piggery values, because the trial results are based on feed intake data, whereas the commercial piggery values are based on feed fed data, which inevitably include some degree of feed wastage.

Based on the end liveweight, ADG, FCR and hot standard carcass weight results, the pigs fed diet $\mathrm{B}(\mathrm{SW})$ performed significantly better than the pigs fed diets A (WB) and D $(\mathrm{BWM})$, which in turn performed significantly better than those fed diet C (WMS).

Skerman et al. (2013c) suggested that a possible explanation for the inferior growth performance of the $\operatorname{diet} \mathrm{C}$ pigs was the omission of a vitamin/mineral premix bucket from this diet mix during the feed manufacturing process. Furthermore, the diet $\mathrm{C}$ premix bucket may have been inadvertently added to the diet $\mathrm{B}$ mix. This explanation is supported by the low mineral levels reported in the diet $\mathrm{C}$ analyses and the high levels reported for diet B. This possible explanation would account for the depressed growth performance and higher fat level of the diet $\mathrm{C}$ pigs, which 

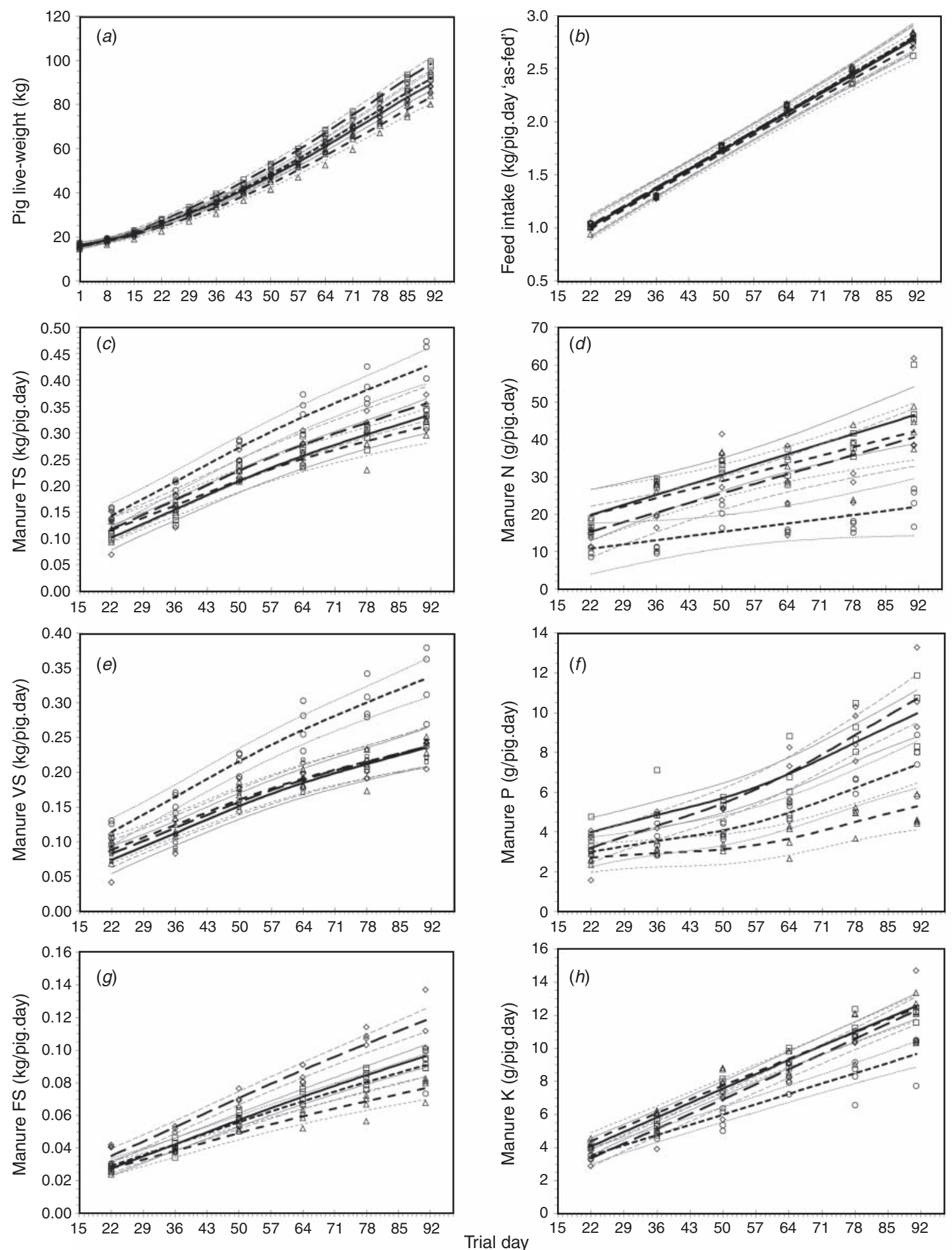

\begin{tabular}{|c|c|c|c|}
\hline - & Diet A - spline & - Diet $\mathrm{A}-\mathrm{Cl}$ & - Diet A \\
\hline & Diet B - spline & - Diet B - Cl & $\therefore$ Diet B \\
\hline & Diet C - spline & $\cdots$ Diet $\mathrm{C}-\mathrm{Cl}$ & $\triangle$ Diet C \\
\hline$--\cdot$ & Diet D - spline & Diet $\mathrm{D}-\mathrm{Cl}$ & - Diet D \\
\hline
\end{tabular}

Fig. 1. Pig liveweight, feed intake and manure total solids, volatile solids, fixed solids (ash), nitrogen, phosphorus and potassium, plotted over the trial period, along with mean diet predictions and $95 \%$ confidence intervals from the linear mixed models fitted to the data. 
would have received marginal levels of essential amino acids during the first 2-3 weeks of growth and may have also suffered from vitamin and/or mineral deficiencies.

Although the pig performance results were not used directly in the model validation process, the results indicate general consistency with the Australian industry benchmarking data. This consistency suggests that the manure production measured in this trial is likely to be representative of typical commercial piggeries operating in Australia.

\section{Manure}

The mean manure production values for each diet are summarised in Table 2. Mean trial data per pig for the manure TS, VS, FS (ash), N, P and K are plotted across the duration of the trial in Fig. 1.

Diet A (WB) had the highest dietary N content, which was reflected in a significantly higher mean $\mathrm{N}$ excretion compared with diets $\mathrm{B}$ and $\mathrm{D}$ (Table 2).

Diet B (SW), which had the highest dietary P content, produced a significantly higher manure FS (ash) output compared with the other diets (Table 2 and Fig. $1 g$ ).

Diet C (WMS) produced significantly less manure FS (ash), on average, compared with the other diets. This result is consistent with diet $\mathrm{C}$ (WMS) having the highest DMD (= digestible energy/gross energy) of the four diets, based on the dietary ingredient database incorporated in the PigBal model. These DMD values are primarily derived from digestible and gross energy values published by Premier Nutrition Products Ltd (2008). The lower dietary P and higher dietary $\mathrm{K}$ concentrations, indicated by the feed analyses, were reflected in diet $\mathrm{C}$ producing significantly less manure $\mathrm{P}$ than all other diets, and significantly more manure $\mathrm{K}$ than diets $\mathrm{B}$ and $\mathrm{D}$.

Pigs fed diet $\mathrm{D}(\mathrm{BWM})$ produced significantly greater masses of manure TS and VS throughout most of the trial period (Fig. 1). This outcome is consistent with barley (the major ingredient in diet D) having the lowest DMD compared with the other major grains used in the trial diets. The pigs fed diet $\mathrm{D}$ (BWM) also produced a significantly higher manure VS/TS ratio. The significantly lower manure $\mathrm{N}$ and $\mathrm{K}$ contents recorded for diet $\mathrm{D}$ are consistent with this diet having the lowest overall dietary $\mathrm{N}$ and $\mathrm{K}$ contents, according to the feed analysis results reported in Table 2.

\section{PigBal model validation}

Plots of measured TS, VS, FS (ash), N, P and K values versus the values predicted by the PigBal model for the four individual diets (A-D) and the combined diet data are shown in Fig. 2. $\mathrm{EF}$ and linear regression parameters $\left(R^{2}\right.$, slope and intercept), as suggested by Mayer and Butler (1993), are provided in Table 3. In combination, these graphs and tabulated data were used to assess the performance of the PigBal model for predicting key parameters relating to piggery manure production.

The EF values for TS range from 0.66 for diet $C$, to 0.91 for $\operatorname{diet} \mathrm{D}$, with an overall $\mathrm{EF}$ of 0.80 for the combined diet data. The slopes and intercepts of the measured versus predicted plots are not significantly different from 1 and 0 , respectively, with the exception of diet $\mathrm{C}$, which has a slope significantly different from 1 . These results suggest that the model generally performed well in predicting TS production, with relatively good agreement between the measured and predicted results (Fig. 2a).

The EF values for VS range from 0.07 for diet $\mathrm{B}$, to 0.90 for diet $\mathrm{D}$, with an overall $\mathrm{EF}$ of 0.70 for the combined diet data. The slopes and intercepts for diets $\mathrm{C}$ and $\mathrm{D}$ are not significantly different from 1 and 0 , respectively, although diet $\mathrm{B}$ has a slope significantly different to 1 , and the combined data and diet A have intercepts significantly different to 0 . These results suggest that although the model did not predict VS as well as TS, it performed well in predicting VS for diets $\mathrm{C}$ and $\mathrm{D}$ and reasonably well for predicting VS for diet A (EF $>0.50)$. Similarly to TS, diet $\mathrm{D}$ shows the best fit between measured and predicted values (Fig. 2c).

The EF values for FS (ash) ranged from 0.64 for $\operatorname{diet} \mathrm{C}$, to 0.94 for $\operatorname{diet} \mathrm{A}$, with an overall $\mathrm{EF}$ of 0.77 for the combined diet data. The slope and intercept for diet B are not significantly different from 1 and 0 , respectively. In the case of the combined data and $\operatorname{diet} \mathrm{C}$, both the slope and intercept are significantly different from 1 and 0 , respectively. Although diets $\mathrm{A}$ and $\mathrm{D}$ both have high EF values ( 0.94 and 0.89 , respectively), they each also have intercepts significantly different from 0 . These results suggest that the model performed reasonably well in predicting the manure FS (ash) excretion (Fig. 2e).

The EF values for $\mathrm{N}$ ranged from -4.40 for $\operatorname{diet} \mathrm{D}$ to 0.39 for diet A, with an overall EF of 0.19 for the combined diets. The slopes and intercepts for all four diets and the combined data were all significantly different from 1 and 0 , respectively. In comparison with TS, VS and FS (ash), this result suggests that there is relatively poor agreement between the measured and predicted results. The negative value for diet $\mathrm{D}$ suggests that the measured mean is a more accurate predictor of $\mathrm{N}$ than the PigBal model. This clearly indicates an unsatisfactory fit for this diet. Although the other diets each have positive EF values, the measured versus predicted plot (Fig. $2 b$ ) shows that the model generally under-predicts lower $\mathrm{N}$ values and over-predicts the higher values. Diet A shows the best fit between measured and predicted values.

The EF values for $\mathrm{P}$ ranged from -12.02 for $\operatorname{diet} \mathrm{C}$, to 0.59 for diet $\mathrm{B}$, with an overall $\mathrm{EF}$ of -0.22 for the combined diets. With the exception of the intercept for diet B, the slopes and intercepts for the other three diets and the combined data were all significantly different from 1 and 0 , respectively. In comparison to TS, VS and FS (ash), this suggests that there is relatively poor agreement between the measured and predicted results. The negative $\mathrm{EF}$ values for diets $\mathrm{C}$ and $\mathrm{D}$ suggest that the measured mean is a more accurate predictor of $\mathrm{P}$ than the PigBal model. This clearly indicates an unsatisfactory fit for these diets. The fit for diet B is relatively good whereas the fit for $\operatorname{diet} \mathrm{A}$ is also reasonable. Assuming that the measured values accurately reflect the manure characteristics, the measured versus predicted regression graph (Fig. 2d) shows that the model generally over-predicts $P$ for all diets.

The $\mathrm{EF}$ values for $\mathrm{K}$ ranged from 0.71 for $\operatorname{diet} \mathrm{B}$ to 0.96 for $\operatorname{diet} \mathrm{A}$, with an overall $\mathrm{EF}$ of 0.87 for the combined diets. Despite the relatively high EF values, only diet B has a slope and intercept not significantly different from 1 and 0 , respectively, whereas diet $\mathrm{D}$ has both a slope and intercept significantly different from 1 and 0 , respectively. The measured versus predicted regression graph (Fig. $2 f$ ) indicates that there is very 

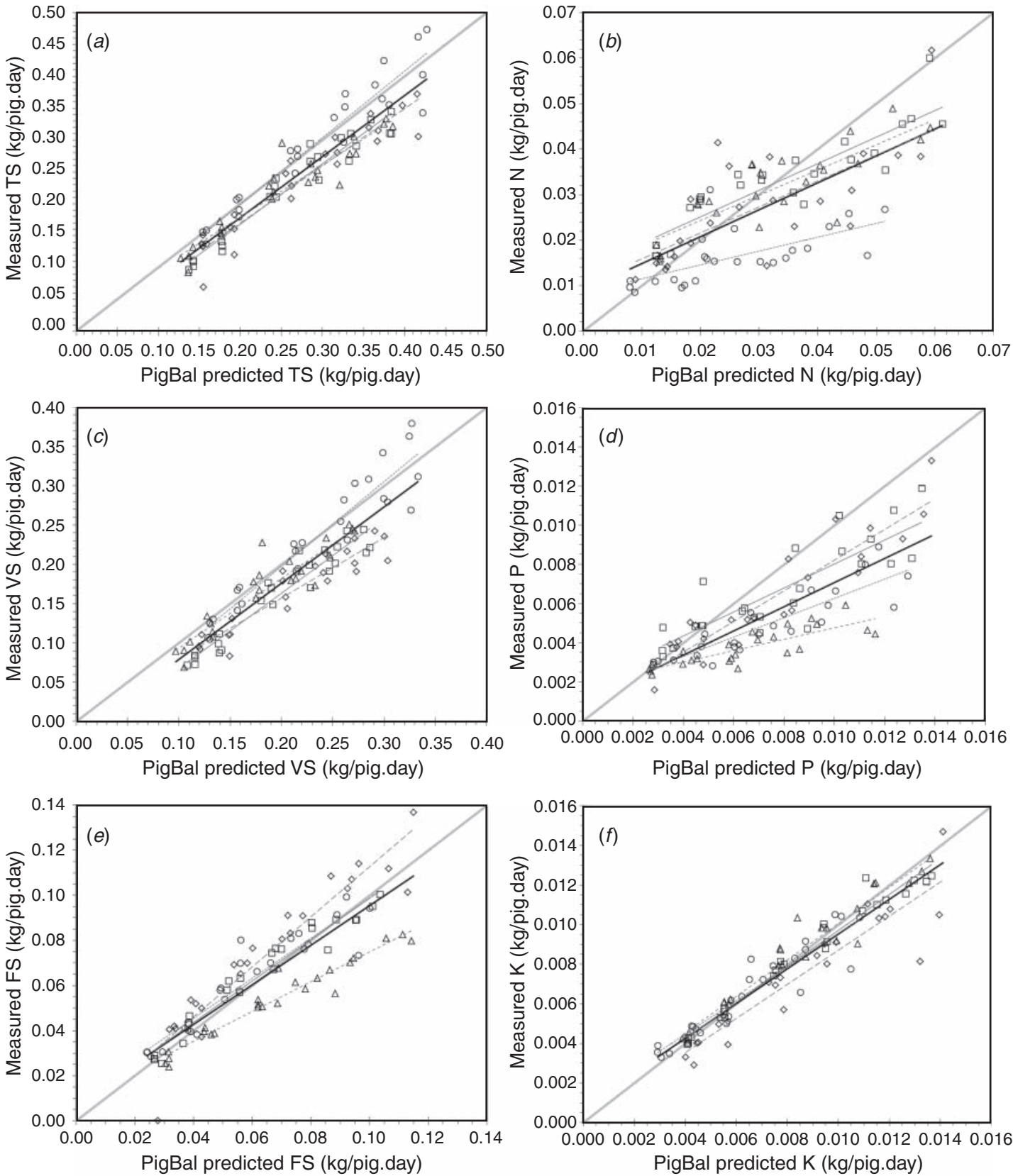

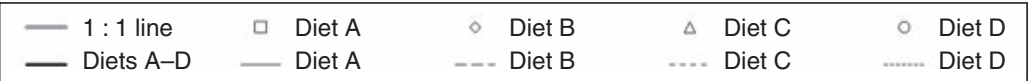

Fig. 2. Linear regression plots of measured total solids, volatile solids, fixed solids (ash), nitrogen, phosphorus and potassium versus values predicted by the PigBal model for the four individual diets (A-D) and the combined diet data.

good agreement between the measured and predicted results, although the model generally over-predicts manure $\mathrm{K}$ production for diet $\mathrm{B}$.

\section{Mass balance analyses}

To more closely examine how the assumed pig composition values used in PigBal affect manure predictions, mass balance analyses were carried out to determine the composition of the pig liveweight gain required to balance the difference between the pigs' dietary intake of FS (ash), N, P and K (based on measured feed intake and feed analysis data) and the values of these traits in the measured manure production (spline values). The results of these mass balance analyses are provided in Table 4 along with the standard values used in the PigBal model and experimental results recorded by Mahan and Shields (1998). 
Table 3. Modelling efficiency (EF) and linear regression parameter values $\left(R^{2}\right.$, slope and intercept) used in the validation of PigBal predictions against measured trial data

*Slope significantly different from 1 or intercept significantly different from $0(P<0.05)$. See Table 2 for definitions

\begin{tabular}{|c|c|c|c|c|c|}
\hline Trait & $\begin{array}{c}\text { Combined } \\
\text { diets }\end{array}$ & $\begin{array}{l}\text { Diet A } \\
\text { (WB) }\end{array}$ & $\begin{array}{c}\text { Diet B } \\
\text { (SW) }\end{array}$ & $\begin{array}{l}\text { Diet C } \\
\text { (WMS) }\end{array}$ & $\begin{array}{l}\text { Diet D } \\
(\mathrm{BWM})\end{array}$ \\
\hline \multicolumn{6}{|c|}{$T S$} \\
\hline EF & 0.80 & 0.75 & 0.68 & 0.66 & 0.91 \\
\hline$R^{2}$ & 0.88 & 0.94 & 0.90 & 0.90 & 0.92 \\
\hline Slope & 0.96 & 0.95 & 0.89 & $0.82 *$ & 1.04 \\
\hline Intercept & -0.013 & -0.021 & -0.008 & 0.015 & -0.009 \\
\hline \multicolumn{6}{|c|}{$V S$} \\
\hline $\mathrm{EF}$ & 0.70 & 0.52 & 0.07 & 0.76 & 0.90 \\
\hline$R^{2}$ & 0.83 & 0.92 & 0.86 & 0.87 & 0.90 \\
\hline Slope & 0.98 & 0.96 & $0.83 *$ & 0.88 & 1.07 \\
\hline Intercept & $-0.021 *$ & $-0.028 *$ & -0.011 & 0.005 & -0.018 \\
\hline \multicolumn{6}{|c|}{$F S(a s h)$} \\
\hline EF & 0.77 & 0.94 & 0.81 & 0.64 & 0.89 \\
\hline$R^{2}$ & 0.79 & 0.95 & 0.93 & 0.94 & 0.88 \\
\hline Slope & $0.86^{*}$ & 0.92 & 1.05 & $0.66^{*}$ & 0.89 \\
\hline Intercept & $0.009 *$ & $0.007 *$ & 0.007 & $0.009 *$ & $0.010^{*}$ \\
\hline \multicolumn{6}{|c|}{$N$} \\
\hline $\mathrm{EF}$ & 0.19 & 0.39 & 0.17 & 0.23 & -4.40 \\
\hline$R^{2}$ & 0.56 & 0.80 & 0.53 & 0.70 & 0.42 \\
\hline Slope & $0.59 *$ & $0.58^{*}$ & $0.57 *$ & $0.56^{*}$ & $0.30 *$ \\
\hline Intercept & $0.009^{*}$ & $0.013 *$ & $0.010^{*}$ & $0.013 *$ & $0.009^{*}$ \\
\hline \multicolumn{6}{|c|}{$P$} \\
\hline $\mathrm{EF}$ & -0.22 & 0.20 & 0.59 & -12.02 & -1.98 \\
\hline$R^{2}$ & 0.66 & 0.73 & 0.86 & 0.67 & 0.79 \\
\hline Slope & $0.62 *$ & $0.61 *$ & $0.78^{*}$ & $0.29 *$ & $0.49 *$ \\
\hline Intercept & $0.001^{*}$ & $0.002 *$ & 0.000 & $0.002 *$ & $0.001 *$ \\
\hline \multicolumn{6}{|c|}{ K } \\
\hline $\mathrm{EF}$ & 0.87 & 0.96 & 0.71 & 0.93 & 0.84 \\
\hline$R^{2}$ & 0.90 & 0.97 & 0.86 & 0.94 & 0.87 \\
\hline Slope & $0.88^{*}$ & $0.91^{*}$ & 0.86 & 0.92 & $0.85^{*}$ \\
\hline Intercept & 0.001 & 0.001 & 0.000 & $0.001 *$ & $0.001 *$ \\
\hline
\end{tabular}

Table 4. Average compositions of liveweight gain (\%) determined by mass balance analysis using trial data

The standard values used in the PigBal model are also presented along with values reported by Mahan and Shields (1998). FS, fixed solids

\begin{tabular}{lccc}
\hline Trait & Mass balance & PigBal $^{\mathrm{A}}$ & $\mathrm{M}$ and $^{\mathrm{B}}$ \\
\hline FS (Ash) & 3.54 & 2.90 & 2.47 \\
$\mathrm{~N}$ & 2.91 & 2.56 & 2.34 \\
P & 0.68 & 0.45 & 0.47 \\
K & 0.28 & 0.24 & 0.09 \\
\hline
\end{tabular}

${ }^{\mathrm{A}}$ Standard values used in PigBal model.

${ }^{B}$ Values derived from Mahan and Shields (1998) for liveweight range from 21.3 to $90.1 \mathrm{~kg}$.

From Table 4, it is clear that the mass balance analysis results are consistently higher than both the standard PigBal and Mahan and Shields (1998) values for each of the four traits.

\section{Discussion}

The PigBal model performed well in predicting the measured manure TS, VS and FS (ash) production, with EF values for the combined diets of $0.80,0.70$ and 0.77 , respectively.

The modelled manure TS and VS values were generally greater than the measured results. One possible explanation for this over-prediction could be VS losses from the manure between excretion and analysis. Although it is not possible to accurately assess the extent of these losses, it seems reasonable to expect that there would have been some VS losses during this period, depending on factors such as temperature, mixing (during sample preparation) and storage time.

In comparison with TS, VS and FS (ash), the PigBal model performed relatively poorly in predicting the measured manure $\mathrm{N}$ production, with an $\mathrm{EF}$ value of 0.19 for the combined diet data. The negative EF value for diet D clearly indicated an unsatisfactory fit. Possible volatilisation losses of ammonium $\mathrm{N}$ from the manure between excretion and analysis could explain some or all of the discrepancy between the measured and modelled results. Based on limited published data, the original PigBal model (Casey et al. 1996) adopted a default value of $10 \%$ total $\mathrm{N}$ loss from manure, between excretion and discharge from piggery sheds.

In comparison with TS, VS and FS (ash), the PigBal model also performed relatively poorly in predicting the measured manure $\mathrm{P}$ production, with an $\mathrm{EF}$ value of -0.22 for the combined diet data. The negative EF values for diets $\mathrm{C}$ and $\mathrm{D}$ and the combined data clearly indicate an unsatisfactory fit.

The model generally over-predicted the manure-P values for all diets. Based on data provided by the commercial company that prepared the feed for the trial, phytate-P (originating from grains) accounted for $30 \%$ to $40 \%$ of the total $\mathrm{P}$ in the four diets. Each of the four diets included $0.01 \%$ (as-fed mass) of the commercial phytase enzyme preparation Phyzyme XP5000 Pigs (Phantom) (500 U phytase $/ \mathrm{kg}$ ). Phytase is commonly added to pig diets to break down the phytate-P so that it becomes available for uptake by the pigs.

Previous research (Omogbenigun et al. 2003; Maguire et al. 2005; Abioye et al. 2010) has shown that the inclusion of phytase in pig diets decreases total $\mathrm{P}$ excretion.

Although commercial phytase products are included in the PigBal diet ingredient database, the model does not currently include any provisions to vary the total $\mathrm{P}$ excretion if phytase is selected as a component of the pig diet. Consequently, one possible explanation for the model over-predicting the manure$\mathrm{P}$ may have been the inability of the PigBal model to account for the higher uptake of dietary-P by the pigs, resulting in lower $\mathrm{P}$ excretion in the manure.

Kerr et al. (2010) conducted five experiments to investigate the ability of different phytase products (Natuphos, OptiPhos, Phyzyme and RonozymeP) to improve P digestibility in finishing pigs, resulting in the development of regression equations for determining $\mathrm{P}$ digestibility for a range of phytase concentrations in the diet. These relationships could potentially be incorporated into the PigBal model to provide more accurate predictions of $\mathrm{P}$ excreted in the manure.

The PigBal model performed well in predicting the measured manure-K production, with an overall EF of 0.87 for the 
combined diet data. Potassium is a conservative element, which is primarily present in the dissolved form in the manure samples and is not subject to losses during the sample collection, storage and subsampling process.

The mass balance analysis (Table 4) indicates consistently higher average concentrations of TS (ash), N, P and K in the pig liveweight gain compared with both the standard PigBal and Mahan and Shields (1998) values. This indicates that, to achieve a mass balance between the measured dietary intake and the manure output values, a higher level of retention in the pig liveweight was required. This result is also consistent with the PigBal model generally over-predicting manure production by partitioning less of the dietary intake components to the pig liveweight gain.

The PigBal and Mahan and Shields (1998) values shown in Table 4 are in relatively close agreement, with the exception of the K values. If the PigBal and Mahan and Shields (1998) values are accurate, this supports the supposition that manure- $\mathrm{N}$ losses may have accounted for some or all of the variation between the measured and modelled manure production results.

The results of this research suggest that the accurate estimates of manure TS and VS provided by PigBal can be used with confidence for designing waste treatment systems and assessing the methane energy potential of anaerobic digestion systems. Despite the apparent over-prediction of manure- $\mathrm{N}$ and $\mathrm{P}$ (assuming that the measured results obtained in this study were accurate), the use of PigBal for sizing land application areas is also likely to be acceptable in most situations, because it appears to result in conservative $\mathrm{N}$ and $\mathrm{P}$ land application rates. Similarly, the use of PigBal for predicting GHG (methane and nitrous oxide) emissions is also acceptable given the accurate predictions of VS production and the apparent over-prediction of $\mathrm{N}$ production, resulting in conservative estimates of nitrous oxide emissions.

Further research evaluating the quantity and composition of pig waste production should consider including some separate collection of urine, faeces and water, in conjunction with acidification of urine to preserve N. Furthermore the individual grains included in the diet should be sampled and analysed to enable more accurate modelling as any inconsistencies between the N, P and K contents of the grains used in the diets and the values adopted in the PigBal feed ingredient database will inevitably contribute to modelling discrepancies. There is also a need to confirm that the feed and manure sample analysis methods accurately account for the phytase-P.

\section{Conclusions}

In summary, the PigBal model provided relatively accurate predictions of the measured TS, VS, FS (ash) and K in the manure samples. However, the performance of the PigBal model for predicting the measured $\mathrm{N}$ and $\mathrm{P}$ in the manure samples was generally less accurate.

The relative accuracy of the TS, VS, FS (ash) and K model predictions suggests that the experimental procedure used in collecting and weighing representative manure samples was not responsible for the discrepancies observed for $\mathrm{N}$ and $\mathrm{P}$. In the case of $\mathrm{N}$, the most likely explanation for the inaccurate predictions is ammonium- $\mathrm{N}$ volatilisation losses between manure excretion and sample analysis. In the case of $\mathrm{P}$, the most likely explanation for the inaccurate predictions was the inability of the model to account for higher pig $\mathrm{P}$ uptake rates resulting from the inclusion of phytase in the trial diets. This could be addressed by including provision for increasing the rate of $\mathrm{P}$ retention by pigs when phytase is included in the PigBal diet.

Notwithstanding the possible limitations of the model identified in this paper, the recently revised version of PigBal, (PigBal 4, Skerman et al. 2013b) is likely be retained as the national industry standard tool for estimating piggery waste production. It is anticipated that it will be used by producers, consultants, industry service providers and government regulatory agencies for designing piggery effluent treatment systems and sustainable reuse areas, evaluating the energy potential from anaerobic digestion of pig effluent, and for estimating GHG emissions for statutory reporting purposes by government. The current version of the model and the user manual, which describes the key equations used in the model calculations, may be downloaded from the Australian Pork Limited website (http://australianpork.com.au/industry-focus/ environment/waste-management-pigbal/, verified 29 December 2014).

\section{Acknowledgements}

This research was conducted under APL Project No. 2010/1011.334 'Validation and development of the PigBal model - Stage 2', which was jointly funded by Australian Pork Limited, the Department of Agriculture, Fisheries and Forestry (Queensland) and the University of Queensland. The financial support provided by these organisations is gratefully acknowledged. Technical support for the metabolic pen trials was provided by Messrs Gary Collman and Ross Knight of DAFF, Toowoomba, with valuable assistance from $\mathrm{Mr}$ Andrew Kelly (DAFF) and other employees of the Centre for Advanced Animal Science (CAAS), University of Queensland, Gatton Campus. The contributions of Dr Paul Jensen and Mr Chris Carney of the Advanced Water Management Centre, University of Queensland and Ms Susan Fletcher of DAFF, Toowoomba, are gratefully acknowledged for assistance with laboratory analysis services and the trial design, respectively.

\section{References}

Abioye S, Ige D, Akinremi O, Nyachoti M, Flaten D (2010) Characterizing fecal and manure phosphorus from pigs fed phytase supplemented diets. The Journal of Agricultural Science 2(4), 3-12.

American Public Health Association (1998) 'Standard methods of examination of water and wastewater.' 20th edn. (American Water Works Association (WPCF), American Public Health Association: Washington, DC)

Barth CL (1985) 'Livestock waste characterization - a new approach', In 'Proceedings of the 5th International Symposium on Agricultural Wastes', St Joseph, MI, USA, sponsored by Agricultural Waste Utilization and Management, American Society of Agricultural Engineers. pp. 286-294.

Butler DG, Cullis BR, Gilmour AR, Gogel BJ (2009) 'ASReml-R reference manual (version 3).' (Queensland Department of Primary Industries and Fisheries, NSW Department of Primary Industries)

Campbell R (2013) Pork CRC benchmarking project results, 'Aussie pork producers coming off the bench'. Australian Pork Newspaper February 2013. Available at http://porkcrc.com.au/aussie-porkproducers-holding-their-own/ [Verified 10 March 2013] 
Casey KD, McGahan EJ, Atzeni MA, Gardner EA, Frizzo RE (1996) 'PigBal version 1.0 - a nutrient mass balance model for intensive piggeries.' (Department of Primary Industries (Queensland): Toowoomba)

Department of Climate Change and Energy Efficiency (2011) 'Australian National Greenhouse Accounts, National Inventory Report 2009, Volume 1, The Australian Government Submission to the UN Framework Convention on Climate Change April 2011.' (Department of Climate Change and Energy Efficiency: Canberra, ACT)

Federal Register of Legislative Instruments F2012L01501 (2012) Carbon farming (destruction of methane generated from manure in piggeries) methodology determination. Carbon Credits (Carbon Farming Initiative) Act 2011.

Kerr BJ, Weber TE, Miller PS, Southern LL (2010) Effect of phytase on apparent total tract digestibility of phosphorus in corn-soybean meal diets fed to finishing pigs. Journal of Animal Science 88, 238-247. doi:10.2527/jas.2009-2146

Maguire RO, Dou Z, Sims JT, Brake J, Joern BC (2005) Dietary strategies for reduced phosphorus excretion and improved water quality. Journal of Environmental Quality 34, 2093-2103. doi:10.2134/jeq2004.0410

Mahan DC, Shields RG (1998) Macro- and micromineral composition of pigs from birth to 145 kilograms of body weight. Journal of Animal Science 76, 506-512.

Mayer DG, Butler DG (1993) Statistical validation. Ecological Modelling 68, 21-32. doi:10.1016/0304-3800(93)90105-2

McGahan EJ, Casey KD (1998) Use of a modified version of the damp model to define the size of pig production enterprises (standard pig units). Paper no. 984126. In 'Proceedings of ASAE Meeting, St Joseph, MI'.

McGahan EJ, Casey KD, Duperouzel D, Smits RJ (2000) Validation of waste estimation theory for intensive pig production systems. In 'Proceedings of the eighth international symposium on animal, agricultural and food processing wastes, Des Moines, Iowa, 9-11 October 2000'. pp. 96-102. (ASAE: St Joseph, MI)

McGahan EJ, Watts PJ, Wiedemann SG (2010) Validation and development of the PigBal Model - literature review. Final report prepared for Australian Pork Limited. APL Project No. 4446. (APL: Canberra, ACT)

Omogbenigun FO, Nyachoti CM, Slominski BA (2003) The effect of supplementing phytase and organic acids to a corn-soybean based diet fed to early-weaned pigs. Journal of Animal Science 81, 1806-1813.

Payne RW, Harding SA, Murray DA, Soutar DM, Baird DB, Glaser AI, Welham SJ, Gilmour AR, Thompson R, Webster R (2011) 'The guide to Genstat release 14, part 2: statistics.' (VSN International: Hemel Hempstead, UK)

Premier Nutrition Products Ltd (2008) 'Premier Atlas, 2008 - ingredients matrix.' (Redwood Business Limited: Rugeley, Staffordshire, UK)

Skerman AG, Willis S, McGahan EJ, Marquardt B (2013b) PigBal 4 - a model for estimating piggery waste production, Department of Agriculture, Fisheries and Forestry (Queensland) and Australian Pork Limited. Available at http://australianpork.com.au/library-resources/researchreports/snapshot-final-reports/ [Verified 2 January 2015]

Skerman AG, Collman GD, Knight R, Willis S, McGahan EJ, Batstone DJ (2013c) Validation and development of the PigBal model-Stage 2, Final report prepared for Australian Pork Limited, APL Project No. 2010/ 1011.334. Department of Agriculture, Fisheries and Forestry, Toowoomba, Queensland.

Verbyla AP, Cullis BC, Kenwad MG, Welham SJ (1999) The analysis of designed experiments and longitudinal data by using smoothing splines. Applied Statistics 48(3), 269-311. doi:10.1111/1467-9876. 00154

Willis S (2010) Validation and development of the PigBal Model - library of feed ingredients. Final report prepared for Australian Pork Limited. APL Project No. 4446. Toowoomba, Queensland. 